\title{
COMPRAR OU ALUGAR: HÁ UMA MELHOR ESCOLHA?
}

Bernardo Alves Furtado'

\section{SINOPSE}

O mercado imobiliário sofre influências de vários fatores de forma simultânea. Ao optar por um financiamento imobiliário para a compra de imóveis no longo prazo, o mutuário se depara com inúmeros parâmetros cujos valores no futuro são desconhecidos. Este texto se insere no contexto de análise de finanças macroeconômicas, modelos do mercado imobiliário e probabilidades de comportamentos futuros diante de incertezas, e busca simplesmente oferecer ao leitor resultados de simulaçóes numéricas que contribuam para sua tomada de decisão.

Palavras-chave: financiamento imobiliário; simulação numérica determinística.

DOI: http://dx.doi.org/10.38116/radar63art3

\section{INTRODUÇÃO}

O mercado imobiliário sofre influências de vários fatores de forma simultânea. Ao optar por um financiamento imobiliário para a compra de imóveis no longo prazo, o mutuário se depara com inúmeros parâmetros cujos valores no futuro são desconhecidos. Haverá apreciação dos imóveis? Os juros vão subir, ou cair? A inflação se manterá comportada em baixos níveis? De todo modo, optar pelo aluguel implica a crença de que os aluguéis não serão mais apreciados que a inflação, por exemplo? Diante de todas essas incertezas, propomos uma simulação numérica que analisa várias possibilidades de comportamento futuro dos parâmetros e quantifica de forma probabilística a melhor opção para o mutuário. O texto completo se encontra na obra publicada em 2020, Tenure Choice: fundamentals and a simulation, ${ }^{2}$ ao passo que aqui são apresentados apenas os principais resultados. Para o caso brasileiro, diante das escolhas de parâmetros realizadas, comprar é mais benéfico em dois terços dos casos.

O mencionado trabalho de Furtado e Souza se insere no contexto de análise de finanças macroeconômicas, modelos do mercado imobiliário e probabilidades de comportamentos futuros diante de incertezas. O estudo busca simplesmente oferecer ao leitor resultados de simulaçóes numéricas que contribuam para sua tomada de decisão. Adicionalmente, a ferramenta de simulação em si também é disponibilizada.

Do ponto de vista de política pública, enfatizamos alguns aspectos relevantes: i) a necessidade inexorável de habitação impacta de forma relevante o orçamento das famílias - ou por meio das prestaçóes, ou pelo pagamento do aluguel, que, conforme mostra o Instituto Brasileiro de Geografia e Estatística (IBGE), em muitos casos supera 30\% da renda familiar; e ii) adicionalmente, a residência da família determina sua localização e, assim, seu acesso aos serviços públicos e às oportunidades no mercado de trabalho. Do lado do setor público, considerada

1. Técnico de planejamento e pesquisa na Diretoria de Estudos e Políticas Setoriais de Inovação e Infraestrutura (Diset) do Ipea. 
a incapacidade das famílias de arcar com esses custos, há a premência de contribuir para a mitigação dessas necessidades de habitação, comumente reunidas na construção do indicador do deficit habitacional.

Nesse contexto de incapacidade das famílias, é consenso na literatura que a participação do poder público é necessária. A atuação pública, portanto, pode ser mais bem informada se compreender melhor todos os parâmetros que influenciam a evolução do mercado imobiliário no médio e longo prazo, e racionalizar a distinção entre processos de aluguel e compra e adequar políticas de acordo com a magnitude das incertezas para financiamentos imobiliários de prazo muito longo.

Ao pensar em políticas públicas, os gestores poderiam considerar, entre outras coisas: i) a incerteza e influência da evolução do mercado futuro de juros; ii) o espaço temporal de resposta do setor construtivo às necessidades de demanda; iii) o comportamento futuro da inflaçáo e do retorno real de aplicaçóes do Tesouro; e iv) a relevância de zoneamento e outras restriçôes urbanísticas na flexibilidade da oferta.

A proposta deste texto utiliza uma simulação numérica determinística. Os passos e detalhes do financiamento imobiliário estão codificados. Comparam-se os gastos com aluguéis no período e a aplicação da diferença entre aluguel e prestação do financiamento com os custos e ganhos do financiamento imobiliário total. O principal resultado considera intervalos e distribuiçóes razoáveis de parâmetros e simula 20 mil combinaçóes.

A ferramenta disponibilizada ${ }^{3}$ permite a análise de um caso individual, a partir de escolhas de parâmetros do próprio usuário, ou de milhares de casos em conjunto. $\mathrm{Na}$ comparação entre o aluguel e o financiamento pelo Sistema de Amortização Constante (SAC) - utilizando-se dos parâmetros escolhidos pelos autores -, a compra do imóvel é mais lucrativa a partir do $165^{\circ}$ mês do financiamento de vinte anos. Ou seja, para períodos curtos, o aluguel é mais benéfico. No longo prazo, mantidas as condiçôes, para o caso exemplificado, financiar o imóvel seria mais vantajoso.

Alternativamente, uma combinação de 20 mil variações de parâmetros também foi testada. Nesse sentido, a incerteza dos valores é substituída pela escolha aleatória de parâmetros entre os intervalos dados e a distribuição escolhida. Com isso, pode-se ter uma alta ou baixa apreciação do imóvel combinada com vários níveis de inflação ou custo de aluguel, por exemplo. Novamente, para as escolhas de intervalos e distribuiçóes realizadas pelos autores, em quase $40 \%$ dos casos o aluguel ofereceria maiores benefícios financeiros (gráfico 1). No restante, o financiamento e a compra do imóvel seriam mais vantajosos.

Na prática, o texto indica que o mercado imobiliário sofre influência de fatores diversos e que a escolha entre as opçôes de alugar ou financiar um imóvel envolve parâmetros e incertezas futuras relevantes. Probabilisticamente, o estudo sugere que financiar imóveis pode ser uma boa opção na maioria dos casos. Entretanto, em inúmeras simulaçôes, o aluguel se mostrou mais benéfico. No fundo, a disponibilização da ferramenta fornece aos leitores melhor compreensão das diferenças entre as alternativas. Adicionalmente, a subseção 2.2 do texto original indica outros fatores que precisam ser considerados.

Do ponto de vista da política pública, fica patente a dificuldade (para profissionais ou amadores) de antever comportamentos futuros de tantas variáveis. Isso impacta sobremaneira a capacidade de realizar políticas habitacionais de longo prazo e de mantê-las sustentáveis. O conjunto de incertezas acerca do comportamento das variáveis aumenta o custo para mutuários, bancos e gestores da política. Alternativas práticas poderiam incluir negociaçóes intermediárias entre estes atores de modo a encurtar o prazo de previsóes. Dessa maneira, contratos de financiamento seriam revistos em prazos menores - por exemplo, de cinco em cinco anos. Assim, tanto credores quanto financiadores trabalhariam com intervalos bem menores de incertezas, minimizando riscos e custos para ambos os lados. 
Não há dúvida, contudo, de que o custo da habitação e o entendimento do aluguel como remuneração do custo imobilizado superam a capacidade de pagamento de grande parte das famílias brasileiras. Portanto, não só pela complexidade desse mercado, mas também pela sua magnitude, e como bem de necessidade primária, políticas públicas de supervisão, monitoramento, informação e mitigação são de fundamental relevância.

\section{GRÁFICO 1}

Histograma de comparação entre comprar ou alugar com parâmetros aleatórios (Em R\$)

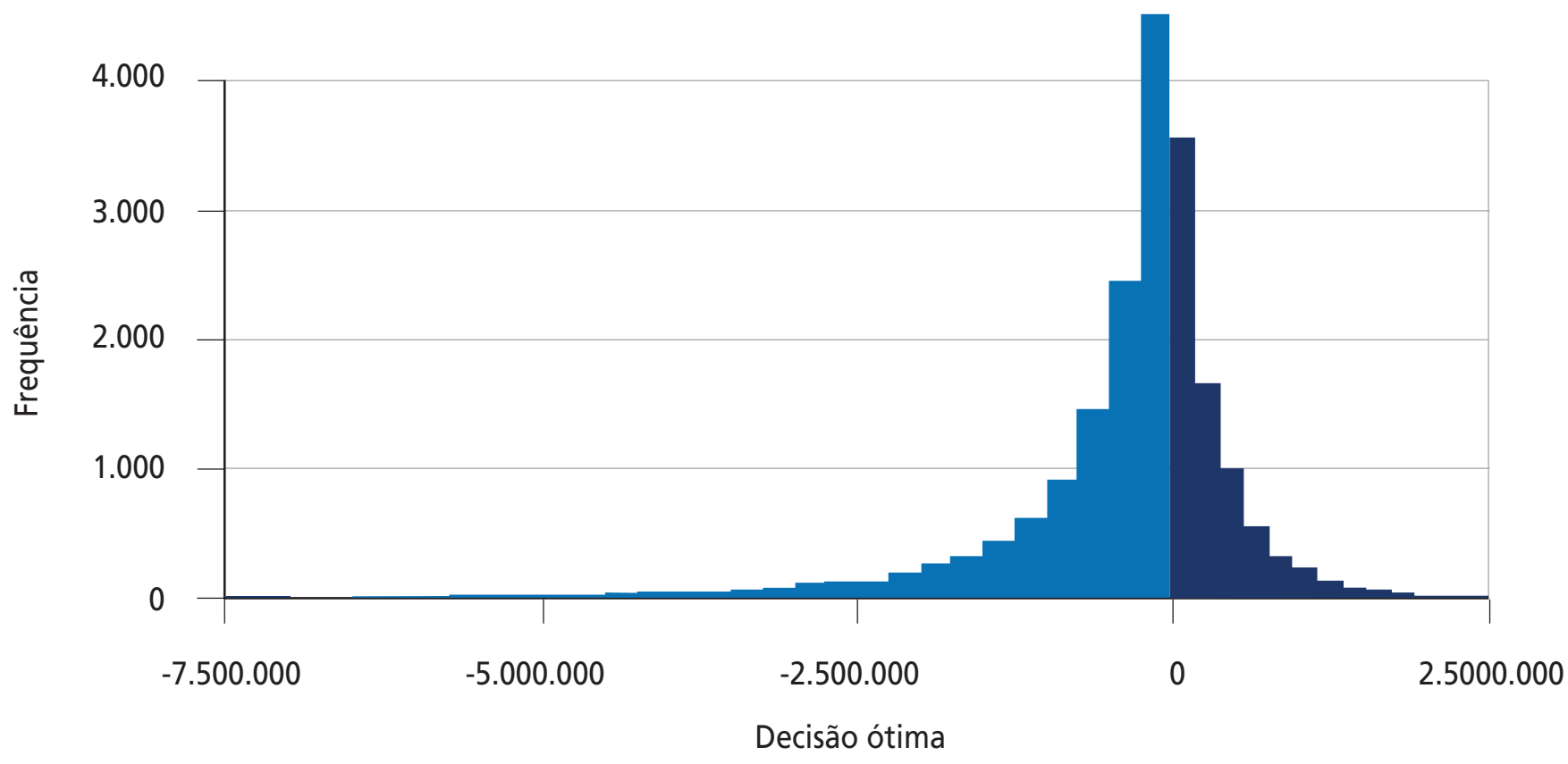

Aluguel Compra

Fonte: Furtado, B. A.; Souza, J. G. M. Tenure choice: fundamentals and a simulation. Brasília: Ipea, mar. 2020. (Discussion Paper, n. 0248). Disponível em: <http://www. ipea.gov.br/portal/index.php?option=com_content\&view=article\&id=35395\&ltemid=444> .

Elaboração do autor.

Obs.: 0 gráfico mostra os resultados da simulação de 20 mil combinações de parâmetros para a escolha entre alugar ou financiar um imóvel. Números positivos representam valores presentes nos quais a escolha de alugar é mais benéfica; números negativos representam simulações nas quais o financiamento do imóvel foi mais vantajoso.

\section{BIBLIOGRAFIA COMPLEMENTAR}

DAVIS, M. A.; NIEUWERBURGH, S. van. Housing, finance, and the macroeconomy. In: DURANTON, G.; HENDERSON, V.; STRANGE, W. Handbook of regional and urban economics. London; New York: Elsevier, 2015. v. 5, p. 753-811.

GLAESER, E. L.; NATHANSON, C. G. Housing bubbles. In: DURANTON, G.; HENDERSON, V.; STRANGE, W. Handbook of regional and urban economics. London; New York: Elsevier, 2015. v. 5, p. 701-751. 
